\title{
REFORMASI MAQASHID SYARIAH KLASIK MENUJU PERSPEKTIF KONTEMPORER
}

\author{
Oleh: \\ H. Abd. Wahid HS1 \\ Email: abdwahidhs06@gmail.com
}

\begin{abstract}
Constructive formulation of Islamic jurisprudence is often deadlocked in addressing contemporary social problems so it demands the birth of reformulation efforts towards understanding and interpreting Islamic teachings not only in the field of jurisprudence but also about figh proposals including the term Maqashid Syariah. The traditional or classical Maqashid concept has limitations and disadvantages as follows: its range is partial, individualistic, and limited in terms of its induction and generality. The classical maqashid sharia reformation towards a contemporary perspective is done by renovating the following things: improvements in the reach, subject, and induction of traditional maqashid. The classifications of contemporary maqashid are general Maqashid (al-Maqashid al-'ammah), special Maqashid (al-Maqashid al-Khassah), and partial Maqashid (almaqashid al-juz'iyyah); reforms from 'safeguard' and 'protection' goals to 'development' and 'human rights'. The purpose of this perspective reform is to be able to respond to global issues, and develop from just 'wisdom behind legal decisions' to practical plans for reform and reform.
\end{abstract}

Key words: Maqashid Syariah, contemporary, classic

\section{Pendahuluan}

Berbicara kaitan Islam dengan realitas, problematika kontemporer yang terus menerus tampil secara dinamis lebih banyak disoroti dari perspektif khazanah keilmuan fikih daripada sorotan dari perspektif akidah dan akhlak. Fikih sebagai konstruksi yuridis Islam lebih berhubungan langsung dengan sisi realitas yang dihadapi oleh masyarakat, meskipun tidak bisa dinafi'kan bahwa tidak sedikit persoalan yang tidak mampu dijawab secara komprehensif melalui kacamata fikih. Banyaknya problematika sosial yang tidak tercover dalam kacamata fikih tersebut,

${ }^{1}$ Dosen Program Studi Pendidikan Bahasa Arab STAI Syaichona Moh. Cholil Bangkalan Madura. 
selain karena terbatasnya cakupan pembahasan yang telah terkodifikasi dalam sebuah karya-karya fikih klasiknya para ulama, juga karena perubahan dan persoalan yang kian beragam yang perbedaan konteks dengan rumusan-rumusan klasik baik dari segi waktu, tempat, budaya maupun kemajuan ilmu pengetahuan kontemporer.

Kebuntuan rumusan konstruktif figh Islamiyah menyikapi problematika sosial kontemporer inilah yang kemudian menuntut lahirnya upaya-upaya reformulasi terhadap pemahaman-pemahaman serta penafsiran ajaran Islam tidak sekedar dalam bidang fikih yang merupakan formulasi konstruksif hukum-hukum Islam, melainkan juga tentang usul fikih yang merupakan akar produsen hukum-hukum fikih, atau bahkan akar yang lebih mendalam dan lebih fundamental yang menjadi pijakan primer hukum Islam. Reformulasi terhadap pemahaman keagamaan agar menjadi pedoman yang kontekstual tentu terkait erat dengan kajian-kajian seputar Maqasid sebagai bagian inti syariat. Maqasih Syariah sebagai aspek inti dari penerapan syariah menjadi fondasi nilai filosofis yang di atasnya lahir variasi-variasi hukum fikih konseptual. Maqasid merupakan usul syariah sedangkan fikih merupakan furu'nya.

Secara etimologi, terma 'Maqasid' berasal dari bahasa Arab مقاصد (maqasid) yang merupakan bentuk jamak dari kata مقصد (maqshad), yang bermakna maksud, sasaran, prinsip, niat, tujuan, tujuan akhir. Terma itu berarti telos (dalam bahasa Yunani). Maqasid Syariah atau Maqasid hukum Islam adalah sasaran-sasaran atau maksud-maksud di balik hukum itu. Bagi sebagian teoritikus hukum Islam, Maqasid adalah pernyataan alternatif dari mashalih atau kemaslahatan-kemaslahatan. Misalnya Abdul Malik alJuwaini, salah seorang kontributor paling awal terhadap teori Maqasid menggunakan istilah Maqasid dan al-mashalih al-ammah (kemashlahatankemaslahatan umum) secara bergantian. ${ }^{2}$ Abu Hamid al-Gazali (w. 505 H/1111 M) mengelaborasi klasifikasi Maqasid yang ia masukkan ke kategori kemashlahatan mursal (al-mashalih mursalah), yaitu kemaslahatan yang tidak disebutkan langsung dalam nash Islam. Pandangan al-Gazali

${ }^{2}$ Abdul Malik Juwaini, Ghiyas al-Umam fi iltiyas al-Zulam, Qatar: Wazarah alSyu'un al-Diniyyah, 1400 H. HIm 253. 
diikuti oleh Fakhr al-Din al-Razi (w.606 H./1209 M.) dan al-Amidi (w. 631 H./1234 M). ${ }^{3}$

\section{Mengenal Maqashid Syariah}

\section{Maqashid dalam Pergulatan Sejarah Intelektual}

Cikal bakal lahirnya konsep Maqashid Syariah sebenarnya sudah muncul pasca era sahabat, hanya saja di era itu kajian Maqashid tidak tematik menjadi satu pembahasan dalam satu kitab. Al-Tirmidzi al-Hakim (w. 296 H/908 M) yang mula-mula memperkenalkan sebuah karya mengenai Maqashid dengan judul bukunya al-Shalat wa Maqashiduha (Shalat dan Maqashidnya), setelah Al-Tirmidzi ada Abu Zaid al-Bakhili (w. 322 H/933 M) mengemukakan sumbangsih pemikirannya tentang Maqashid dalam bidang muamalah dengan judul karya al-Ibanah 'an 'ilal al-Diyanah, disusul setelahnya oleh Al-Qaffal al-Kabir (w. 365 H/975 M) dengan sebuah karya berjudul Mahasin al-Syara' $i$ ', lalu di generasi selanjutnya ada Ibnu Babawaih al-Qummi (w. $381 \mathrm{H} / 991 \mathrm{M}$ ) juga menulis buku tentang Maqashid dengan judul 'Ilal al-Syara'i' serta Al-'Amiri al-Failasuf yang memperkenalkan karyanya seputar Maqashid yang berjudul al-I'lam bi Manaqib al-Islam. ${ }^{4}$

Demikian beberapa karya mengenai Maqashid Syariah yang muncul dalam kisaran abad ke 3 dan ke 4 . Hanya saja jangkauan kajiannya tidak terkonsep secara utuh sebagaimana Maqashid Syariah yang dipopulerkan oleh ulama pakar Ushul Figh di abad setelahnya seperti al-Juwaini, AlGhazali, Al-Qarafi, dan Abu Ishaq al-Syathibi serta beberapa cendekiawan muslim lain yang memiliki andil besar dalam perumusan Maqashid Syariah.

Abad ke 5 menjadi babak baru dinamika kajian Maqashid. Banyak cendekiawan yang mulai merumuskan konsep-konsep mengenai Maqashid Syariah secara tematik dan sistematis sebagai jawaban atas kompleksitas problematika sosial yang tidak dapat terakomodir oleh rumusan-rumusan literal sebelumnya. Menjelang akhir abad ke 5, adalah Abu al-Ma'ali al-

${ }^{3}$ Jasser Auda, membumikan Hukum Islam Melalui Maqasih Syariat, Bandung: Mizan Pustaka. Hlm 33.

${ }^{4}$ Jasser Audah, Membumikan Hukum Islam Melalui Maqashid Syariah. Bandung: Mizan Pustaka. 2008. Hlm 49. 
Juwaini (w. 478 H/1085 M) melalui sebuah risalah Ushul Figh berjudul alBurhan fi Ushul al-Figh mulai mempromosikan gagasan tentang klasifikasi kebutuhan yang tegaskannya sebagai Ushul al-Syariat menjadi lima tingkatan, yaitu: dlaruri (kebutuhan pokok), hajat al-'ammah (kebutuhan publik), mukramat (perilaku moral), mandub (anjuran-anjuran), dan sesuatu yang tidak tercantum secara khusus dalam kategori di atas. ${ }^{5}$ Al-Juwaini mengemukakan bahwa Maqashid hukum Islam adalah memelihara ('ishmah) keimanan, jiwa, akal, keluarga dan harta. ${ }^{6}$

Teori Maqashid Al-Juwaini dilanjutkan muridnya bernama Abu Hamid al-Ghazali (w.505 H/1111 M) melalui karangannya, al-Mustashfa. Melalui kitab ini, al-Ghazali mengurutkan klasifikasi ushul al-syariah-nya al-Juwaini sesuai tingkat urgensinya, yaitu sebagai berikut: 1) agama, 2) jiwa, 3) akal, 4) keturunan, dan 5) harta. Al-Ghazali adalah cendekiawan yang memperkenalkan istilah 'penjagaan' (muhafadzah/hifdz) dan mengemukakan bahwa setiap bentuk penjagaan atas lima pokok tujuan syariah di atas adalah mashlahah. Sedangkan yang berpotensi merusak eksistensi lima hal tersebut sebagai mafsadah. ${ }^{7}$ Pasca al-Ghazali, cendekiawan yang memiliki kontribusi besar terhadap perkembangan Maqashid adalah Al-'Izz Ibn 'Abd al-Salam (w. 660 H/1209 M) melalui sebuah karyanya berjudul Qawa'id al-Ahkam fi Mashalih al-Anam.

Gemilangnya perkembangan gagasan Maqashid di kisaran abad ke 5 hingga abad ke $8 \mathrm{H}$ mencapai puncaknya setelah munculnya Abu Ishaq alSyathibi ( w. 790 H/1388 M) dengan sebuah karya berjudul al-Muwafaqat fi Ushul al-Syariah. Dengan model terminologi kajian yang nyaris serupa dengan al-Juwaini dan al-Ghazali tersebut, al-Syathibi mempromosikan formulasi penting bagi posisi Maqashid Syari'ah dalam hukum Islam. Ketika sebelum al-Syathibi Maqashid hanya diposisikan sebagai mashalih almursalah (kemaslahatan lepas; tidak teratur dalam Qur'an maupun Hadits), maka gagasan al-Syathibi mereposisinya menjadi bagian dari dasar-dasar hukum Islam. Al-Syathibi menilai bahwa Maqashid merupakan pokokpokok agama (Ushul al-Din), kaidah-kaidah syariah (Qawaid Syariah), dan 80.

${ }^{5}$ Al-Juwaini, al-Burhan fi ushul al-Fiqh. Beirut: Dar al-Kutub al-Islami, 1997. Juz II Hlm ${ }^{6}$ ibid

${ }^{7}$ Abu Hamid al-Ghazali, al-Mustashfa. Hlm 438. 
nilai-nilai universal agama (Kulliyat al-Millah) ${ }^{8}$. Dengan al-Muwafaqat-nya yang melengkapi banyak aspek dari gagasan Maqashid sebelumnya, buku tersebut lalu menjadi buku standart Maqashid Syariah di kalangan ulama hingga abad ke $13 \mathrm{H} / 20 \mathrm{M} .^{9}$

\section{Konsep Maqashid Syariah Klasik}

Sebagaimana disampaikan sebelumnya bahwa perkembangan Maqashid dalam pergulatan sejarah pemikiran ulama klasik secara umum terakomodir dalam gagasan fundamentalnya al-Syathibi melalui karyanya al-Muwafaqat fi Ushul al-Syariat dengan berprinsip pada terminologi cendekiawan ushul syariah pendahulunya yaitu al-Juwaini dan al-Ghazali yang lalu dilengkapi dengan gagasan brilian al-Syathibi sendiri. Kendati ada perbedaan varian sudut pandang dalam memposisikan Maqashid, -alGhazali menilainya sebagai mashalih mursalah secara umum konsep Maqashid Syariah berangkat dari konsensus bahwa keseluruhan aturan syariat adalah dalam rangka mewujudkan kemaslahatan bagi umat baik di dunia maupun di akhirat ${ }^{10}$. Intinya, titik pijak kajian Maqashid Syariah adalah apa yang disebut dengan al-mashlahat.

Al-Syathibi melalui al-Muwafaqat Fi Ushul al-Syariat menegaskan bahwa keseluruhan ketetapan atau aturan syariat itu dalam rangka memelihara eksistensi Maqashid (tujuan) daripada syariat itu sendiri dalam kehidupan. Tujuan yang hendak dicapai dibalik ketentuan syariat (Maqashid Syariat) diklasifikasi menjadi tiga varian kebutuhan yang disebutknya sebagai al-kulliyat al-syariat, yaitu; 1) dlaruriyyat (primer), 2) hajiyyat (sekunder), dan 3) tahsiniyyat (tersier)11. Dalam dlaruriyyat ditampilkan bahwa tujuan syariat adalah untuk menjaga eksistensi lima hal (dlaruriyyat al-khams) yaitu: hifdz al-din (menjaga agama), hifdz al-nafs (menjaga jiwa), hifdz al-nasl (menjaga keturunan), hifdz al-maal (menjaga harta benda), dan hifdz al-'aql (menjaga akal pikiran). Sedangkan dimensi hajiyyat dan tahsiniyyat sebagai aspek yang diperjuangkan dalam rangka

\footnotetext{
${ }^{8}$ Al-Syathibi, al-Muwafaqat fi Ushul al-Syariat. Juz II Hlm 6

9 Jasser Auda, Membumikan Hukum Islam Melalui Maqashid Syariah. Bandung: Mizan Pustaka. 2008. Hlm 56.

${ }^{10}$ Al-Syathibi, al-Muwafaqat fi Ushul al-Syariat. Juz III Hlm 220

11 ibid.
} 
mengimplementasikan dan mengembangkan dlaruriyyat al-khams itu. Rumusan al-Syathibi inilah yang menolong verifikasi mana yang masuk kategori ushul dan furu' dalam syariat.

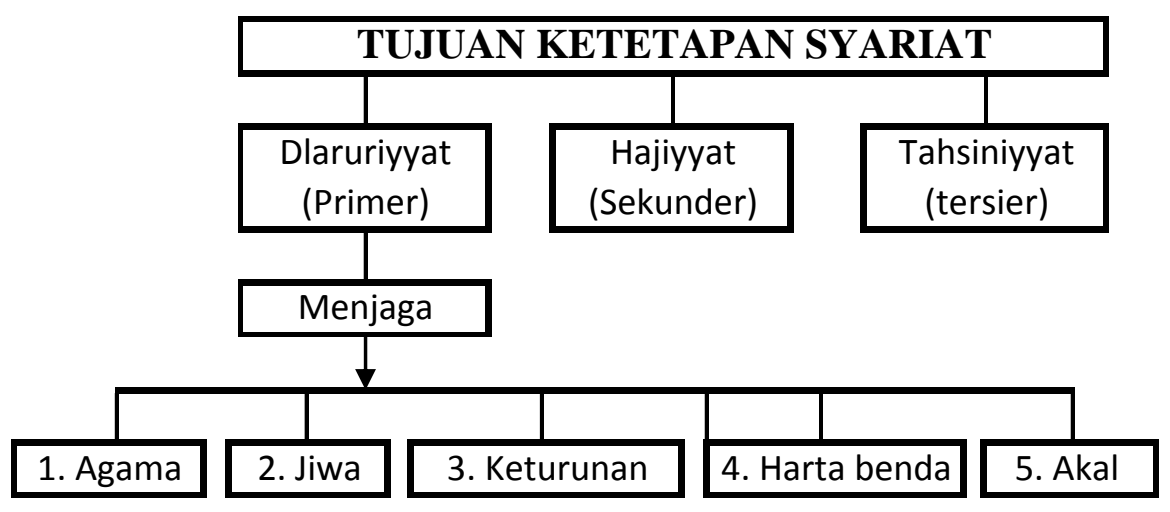

\section{Kontemporisasi Maqashid Syariah}

Perubahan background sosial yang sangat dinamis sebagai segmen alokasi ketentuan-ketentuan yuridis fikih yang diproduksi dari teori Maqashid Syariat tradisional melahirkan pembaharuan pradigmatik tidak sekadar mengenai varian furu' tapi juga mengenai fitur-fitur urgen dalam kerangka ushul yang tersaji melalui Maqashid Syariat yang selama berabadabad dipopulerkan oleh cendekiawan muslim. Abad ke $20 \mathrm{M}$ telah menampilkan beberapa gagasan segar baru yang dinilai lebih relevan dengan persoalan-persoalan global yang aktual. Para teoritikus komtemporer mula-mula menampilkan kritik terhadap klasifikasi Maqashid tradisional sebagaimana dipopulerkan al-Syathibi. Sajian tentang kritik tersebut sebagaimana dipopulerkan Prof. Jasser Auda antara lain²;

\section{a. Parsialitas Jangkauan Maqashid}

Jangkauan tradisional meliputi seluruh hukum Islam. Tetapi, upaya para penggagas Maqashid tradisional itu tidak memasukkan maksud khusus dari suatu atau sekelompok nash/hukum yang meliputi topik

12 Jasser Auda, Membumikan Hukum Islam Melalui Maqashid Syariah. Bandung: Mizan Pustaka. 2008. Hlm 36. 
fikih tertentu. Menurut kalangan cendekiawan kontemporer, jangkauan Maqashid idealnya direnovasi menuju perbaikan yang lebih sistematis dalam bidang klasifikasi jangkauannya.

Klasifikasi kontemporer membagi Maqashid menjadi tiga tingkatan: 1) Maqashid Umum (al-Maqashid al-'Ammah), adalah Maqashid yang dapat ditelaah di seluruh bagian hukum Islam seperti rumusan Maqashid tradisional, ditambah usulan Maqashid baru seperti 'keadilan' dan 'kemudahan'. 2) Maqashid Khusus (al-Maqashid al-Khassah), adalah Maqashid yang dapat diobservasi di seluruh isi 'bab' hukum Islam tertentu, seperti kesejahteraan anak dalam hukum keluarga; perlindungan dari kejahatan dalam hukum kriminal; dan perlindungan dari monopoli dalam hukum ekonomi. 3) Maqashid Parsial (al-Maqashid al-Juz'iyyah), yaitu maksud-maksud di balik suatu nash atau hukum tertentu, seperti maksud mengungkapkan kebenaran dalam mensyaratkan jumlah saksi tertentu dalam kasus hukum tertentu, misalnya.

\section{b. Individualisme 'Subjek Hukum' Maqashid}

Maqashid tradisional lebih berkaitan dengan individu dibandingkan dengan keluarga, masyarakat atau umat manusia. Dalam rangka memperbaiki kekurangan teori Maqashid terkait jangkauan orang yang diliputi (yaitu individual), maka ide Maqashid oleh cendekiawan muslim modern dan kontemporer diperluas hingga mencakup jangkauan manusia yang lebih luas yaitu masyarakat, bangsa, bahkan umat manusia. Seperti Ibnu 'Asyur yang memprioritaskan Maqashid yang berkaitan dengan kepentingan 'bangsa' atau umat di atas Maqashid seputar kepentingan individual. Rasyid Ridho memasukkan isu 'reformasi' dan 'hak-hak wanita' dalam teori Maqashidnya; serta Yusuf al-Qardlawi yang banyak membahas tentang 'martabat dan hak asasi manusia' dalam kajian Maqashidnya.

Lebih lanjut, Jasser Auda mengatakan bahwa pemekaran jangkauan Maqashid membuatnya dapat merespon isu-isu global, serta 
membuatnya berkembang dari sekadar 'hikmah dibalik keputusan hukum' menuju 'rencana praktis untuk reformasi dam pembaruan'13

\section{c. Reformasi Induksi dan Keumuman Maqashid}

Maqashid tradisional dideduksi dari kajian 'literatur fikih' ketimbang sumber-sumber syariat (al-Qur'an dan Sunnah). Selain itu, klasifikasi Maqashid tradisional tidak memasukkan nilai-nilai yang paling umum seperti keadilan dan kebebasan. Berangkat dari hasil koreksi tersebut, cendekiawan kontemporer memperkenalkan teori Maqashid baru yang langsung digalinya dari nash. Menurut Jaser Auda, pendekatan ini akan memungkinkan Maqashid melampaui historisitas keputusan fikih dan merepresentasikan nilai serta prinsip umum dari nash. Maka, hukum-hukum yang detail (ahkam tafshiliyyat) dapat digali dari prinsip-prinsip yang menyeluruh (kulliyat).

Demikian beberapa kritik serta sebagian solusi yang disampaikan Jaser Auda sebagai salah satu cendekiawan yang menjadi salah satu representasi gagasan kontemporerisasi Maqashid Syariah melalui karyanya berjudul Maqasid Shariah as Philosophy of Islamic Law; A Systems Approach, sebuah karya monomental Jaser Auda yang menjadi media publikasi gagasannya tentang Pendekatan Sistem (A Systems Approach) dalam menggali hukum Islam.

Yang tidak kalah urgen tentang gagasan kontemporerisasi Maqashid adalah konsep rumusan baru yang diviralkan oleh cendekiawan Maqashid modern berkenaan dengan sudut pandang pemaknaan terhadap dlaruriyyat al-khams yang selama ini menjadi standar pemahaman yang diperkenalkan sejak abad ke $5 \mathrm{H}$ tersebut. Cendekiawan Maqashid modern menggunakan terminologi kontemporer dalam memaknai dlaruriyyat meskipun diakui oleh Jaser Auda bahwa tidak sedikit mendapatkan penolakan dari kalangan cendekiawan yang lain. Konsep terminologi modern tersebut antara lain sebagai berikut: Reformasi dari tujuan 'Penjagaan' dan 'Perlindungan' menuju 'Pengembangan' dan 'Hak-Hak Asasi'. 
Sebagaimana dimaklumi bahwa dalam perkembangan Maqashid di abad ke $5 \mathrm{H} / 12 \mathrm{M}$, al-Ghazali memperkenalkan istilah hifdz atau muhafadzah (menjaga atau melindungi) terhadap dlaruriyyat al-khams. Dalam perkembangan Maqashid di abad ke $20 \mathrm{M}$, terminologi yang digunakan dalam memposisikan dlaruriyyat al-Khams dari yang semula menggunakan istilah 'penjagaan' atau 'perlindungan' (hifdz/muhafadzah) menuju 'pengembangan' dan 'hak-hak asasi'. Hifdz al-Din misalnya, yang dalam Maqashid tradisional dimaknai sebagai konsep 'perlindungan terhadap agama' dalam kacamata kontemporer diinterpretasikan ulang menjadi konsep yang sama sekali berbeda, yaitu 'kebebasan kepercayaan' (freedom of faiths) menurut istilah yang digunakan Ibn 'Asyur,14 atau 'kebebasan berkeyakinan' dalam ungkapan kontemporer lain.

Hifdz al-Nafs dan Hifdz al'Irdl yang semula bermakna 'perlindungan jiwa raga' dan 'perlindungan kehormatan' dalam perkembangan kontemporer diganti oleh 'perlindungan hak asasi manusia' dan 'perlindungan harkat dan martabat manusia' yang kemudian menjadi bagian dari Maqashid Syariat, Hifdz al-Nasl yang dalam khazanah bermakna 'perlindungan keturunan' dalam perkembangannya berubah menjadi teori berorientasi keluarga. Ibnu 'Asyur menjadikan terma 'peduli keluarga' sebagai Maqashid hukum Islam. Begitu juga Hifdz al-Maal yang semula bermakna 'perlindungan harta' berkembang menjadi istilah-istilah sosio ekonomi yang lebih familiar dan milenial seperti 'pengembangan ekonomi', 'bantuan sosial', 'distribusi uang', 'masyarakat sejahtera' dan 'pengurangan perbedaan antar kelas ekonomi sosial'. ${ }^{15}$

Begitu pula konsep Hifdz al-'Aql yang dalam khazanah tradisional klasik dimaknai 'penjagaan/perlindungan akal fikiran' dalam perkembangannya juga memasukkan konsep 'pengembangan pikiran ilmiah' sebagai bagian dari Maqashid tersebut pun demikian 'perjalanan menuntut ilmu', 'melawan mentalitas taklid' dan mencegah

${ }^{14}$ Ibnu 'Asyur, Maqashid Syariah al-Islamiyyah. Hlm 292.

${ }^{15}$ Quttub Sano, Qiraat Ma'rifiyyat fi al-Afkar al-Ushuli, edisi 1. Kuala Lumpur: Dar alTajdid. 2003. Hlm 157 
mengalirnya tenaga ahli ke luar negeri' yang juga senafas dengan gagasan Hifdz al-'Aql.16 Lahirnya gagasan-gagasan baru tersebut dimaksudkan untuk menerjemahkan ulang positioning sumber-sumber ushul syariat agar tidak kehilangan aspek relevansinya dengan kemajuan dan tantangan global.

\section{Penutup}

Reformasi Maqashid Syariah klasik menuju perspektif kontemporer merupakan upaya fundamental untuk senantiasa memelihara eksistensi jangkauan fikih sebagai pedoman individual, spiritual, dan sosial. Problematika sosial berubah kian dinamis yang tidak tercover dalam yurisprudensi fikih klasik lantaran perbedaan dalam jangkauan ruang waktu, tempat dan kondisi sosial yang melatarbelakanginya, memberi peluang besar untuk tidak sekadar dicermati melalui pendekatan qiyas dan lainnya, akan tetapi juga melalui upaya reformasi dalam hal-hal yang prinsip dalam formulasi hukum Islam yaitu perubahan perspektif di sektor filsafat hukum Islam yang terangkum dalam terminologi Maqashid Syariah.

Formulasi Maqashid Syariah klasik yang menjadi landasan filosofis konstruksi hukum Islam sejak puluhan abad lalu dinilai seringkali mencapai titik stagnasi ketika dihadapkan pada persoalan kekinian dan oleh karenanya senantiasa dilakukan perbaikan dan perubahan untuk tetap memelihara eksistensi jangkauan Maqasid Syariah, inovasi perspektif Maqashid klasik ini di antaranya dalam hal reformasi dari Maqashid yang semua bermakna 'Penjagaan' dan 'Perlindungan' menuju 'Pengembangan' dan 'Hak-hak asasi', begitupula reformasi dalam induksi dan keumuman Maqashid, subjek hukum, dan jangkauan hukum Maqashid Syariah. Dilaluinya proses ini tidak lain untuk mewujudkan eksistensi hukum Islam di tengah-tengah kehidupan global, membuatnya dapat merespon isu-isu global, serta membuatnya berkembang dari sekadar 'hikmah di balik keputusan hukum' menuju 'rencana praktis untuk reformasi dan pembaruan.

16 Jaser Auda. Membumikan Huku Islam Melalui Maqashid Syariah. Bandung: Mizan Pustaka. 2008. Hlm 57. 


\section{DAFTAR PUSTAKA}

Abu Hamid al-Ghazali. Tt. al-Mustashfa.

Al-Juwaini. 1997. al-Burhan fi ushul al-Figh. Beirut: Dar al-Kutub al-Islami.

Al-Syathibi. Tt. al-Muwafaqat fi Ushul al-Syariat.

Asyur, Ibnu. Tt. Maqashid Syariah al-Islamiyyah.

Auda, Jasser. 2008. Membumikan Hukum Islam Melalui Maqashid Syariah. Bandung: Mizan Pustaka. 2

Sano, Quttub. 2003. Qiraat Ma'rifiyyat fi al-Afkar al-Ushuli, edisi 1. Kuala Lumpur: Dar al-Tajdid. 
Jurnal Pendidikan dan Pranata Islam 